\title{
Traveller's thrombosis
}

\author{
P L J Kesteven
}

Consultant Haematologist, Freeman Hospital, High Heaton, Newcastle upon Tyne

NE7 7DN, UK

Introductory article

\section{Travel as a risk factor for venous thromboembolic disease: a case-control study}

\author{
E Ferrari, T Chevallier, A Chapelier, M Baudouy
}

Background. The link between travel and the risk of venous thromboembolic disease (VTED) has been widely suspected. However, only cases or series of cases have been reported in the literature. Study objectives. By means of a case-control study, we sought to confirm this relationship and to determine the main features, if any, of these posttravel VTEDs. Design. The history, in particular the history of recent travel, of 160 patients presenting in our department with VTED was scrupulously investigated. All journeys undertaken during the preceding 4 weeks and lasting $>4 \mathrm{~h}$ by whatever means of transport were considered. The same questionnaire was submitted to a control group. Results. When the two groups of patients are compared, a history of recent travel is found almost four times more frequently in the VTED group $(p<0.0001)$. The odds ratio for having a VTED in patients who traveled was 3.98 (95\% confidence interval, 1.9 to 8.4). Means of travel used included the train in 2 cases, airplane in 9 , and car in 28. Mean duration of travel was $5.4 \pm 2.1 \mathrm{~h}$. These posttravel VTEDs are not confined to a specific location, seem to involve no particular predisposition, and are more often "idiopathic." This fact supports the hypothesis that travel alone can produce vein clot formation. Conclusions. A history of recent travel is a risk factor for VTED. Posttravel venous thrombotic events can occur after short journeys in patients with no other risk factors or concomitant disease. (Chest 1999;115:440-4)

Over the last decade details of at least 200 cases of traveller's thrombosis have been reported in separate publications. Although these cases were selected by different methods, all studies used a similar definition: symptomatic cases of venous thromboembolism (VTE), usually deep venous thrombosis (DVT) or pulmonary embolus, objectively diagnosed, presenting within 4-5 weeks of prolonged travel. ${ }^{1-4}$

In their paper Ferrari et al provide the first published report of a prospectively studied series of patients with VTE in whom travel was a likely precipitating factor. ${ }^{3}$ Furthermore, they were able to study a group of control patients in order to establish the relative risk, compared with hospital patients, of traveller's thrombosis. Unfortunately, a study designed to establish the relative risk of this complication amongst passengers has yet to be performed. This was a timely study, casting doubt on the previously widely held assumption that traveller's thrombosis occurred predominantly after flying. This paper also provided well documented evidence that traveller's thrombosis was likely to be associated with other risk factors for VTE present before travel.

There remains a series of further questions which need to be answered:

(1) Is traveller's thrombosis a real entity? In other words, is there now an established link between VTE and travel by whatever mechanism? If there is, what is the incidence of this problem? And does this condition behave in a similar fashion to other more common and better researched forms of VTE such as postoperative or post-partum cases?

(2) If VTE can be precipitated by travel, is flying more dangerous in this respect than other forms of transport?

(3) Finally, if this is shown, what could be the cause(s) and what can be done about it?

Venous thromboembolic disease

The annual incidence of VTE in northern European populations has been estimated to be between 1.6 and 1.8 per $1000 .{ }^{56}$ Others have used the more approximate figure of 1 per 1000 per annum. ${ }^{7}$ The age of the patient is an extremely important determinant of this incidence, being virtually unknown in children and climbing from less than 1 per 10000 in young adults to more than $3-5$ per 1000 in subjects over the age of 60 years. ${ }^{8}$

There is now a more or less generally accepted list of risk factors for VTE, in addition to venous stasis and age. These include previous or strong family history of VTE, pregnancy and the puerperium, malignancy, hormone therapy, trauma and, more recently, an expanding array of inherited blood disorders. Epidemiological studies have produced estimates of the relative risk of each (table 1) and a great deal of current research in this area is directed towards uncovering the 


\begin{tabular}{lccc}
\multicolumn{5}{l}{ Table 1} & Risk factors for venous thromboembolism (VTE) \\
\hline & $\begin{array}{l}\text { Relative } \\
\text { risk }\end{array}$ & $\begin{array}{l}\text { Population } \\
\text { attributable risk } \\
(\%)\end{array}$ & $\begin{array}{l}\text { Prevalence } \\
(\%)\end{array}$ \\
\hline Puerperium & 14 & 12 & 1 \\
Immobility & 11 & 15 & 2 \\
Malignancy & 7 & 10 & $2-3$ \\
Surgery/trauma & 6 & 16 & 4 \\
OCP & $4-6$ & $50-67$ & 40 \\
HRT & 4 & $40-50$ & $25-40$ \\
Pregnancy & 4 & 10 & 5 \\
\hline OCP = oral contraceptive pill; HRT = hormone replacement therapy.
\end{tabular}

effect of combinations of these risks. Rosendaal has taken this further, postulating that VTE is usually a "multiple hit" disorder requiring, for its clinical expression, the presence of several of these risk factors simultaneously. ${ }^{8}$

One of the best researched forms of VTE is in postoperative patients. Venous sludging during anaesthesia is thought to induce a nidus of blood clot behind a venous valve. If conditions are prothrombotic this thrombus will grow proximally, first to other calf veins, then to femoral and, in extreme cases, iliac veins. Some DVTs do appear to start in the thigh but these are a minority. It is a widely held belief that calf DVTs only rarely cause clinically significant pulmonary emboli; large pulmonary embolisms generally arise from more proximal veins.

\section{Is the association of VTE with travel real?}

It has been recognised since the days of Virchow that VTE is frequently precipitated by venous stasis induced by immobility. ${ }^{9}$ In 1940 the possibility of a link between sitting and the development of VTE was raised by Simpson, a London pathologist. ${ }^{10}$ During the blitz he noted a high incidence of pulmonary embolism in those who had been sleeping overnight in bomb shelter deck chairs. The author also noted that this phenomenon disappeared when the deck chairs were replaced by bunks.

The earliest suggestion that travel may precipitate VTE came from a vascular surgeon in Boston who presented five case reports of DVT after prolonged sitting. ${ }^{11}$ These were after a car trip in two, a prolonged flight in two (and, interestingly, as discussed below, these were both return flights), and a visit to the theatre in one. More recently there has been a report of increased incidence of DVT in commuters caught up in the 1995 Paris bus drivers' strike. ${ }^{12}$

The first published series involving illness during a commercial flight appeared in 1968 and reported 42 cases presenting immediately after a flight to a hospital near Heathrow over a three year period. Only one of these had VTE; most were suffering from cardiac or infectious problems. ${ }^{13}$ More recently, in a series of 104 natural deaths occurring during or immediately after flights 12 were found to be caused by pulmonary embolism. ${ }^{14}$

The possibility that traveller's thrombosis, amongst passengers of commercial airlines at least, may be precipitated by other factors was proposed by Cruikshank et al who published three case reports of VTE after flying and coined the phrase "economy class syndrome". ${ }^{15}$ This raised the notion that the degree of being cramped may be important aetiologically. However, it should be noted that one of the three cases had travelled in business class, whereas two of the cases were doctors.
On this evidence they could equally well have called their paper "travelling doctor syndrome" which is, of course, not nearly as noteworthy.

In the last decade there have been several large series of such cases reported in literature reviews, retrospective case analyses, and the similar (though prospective and controlled) Ferrari study. ${ }^{1-416}$ There have been no published prospective clinical studies in which a series of asymptomatic travellers was examined for the development of either VTE or activation of the thrombotic system.

Thus, the evidence that does exist on this subject is largely circumstantial. However, the mass of accumulated literature over the last 40 years, including the more recent large series, makes the likelihood of such an association so strong as to be virtually irrefutable.

\section{Incidence of travel associated VTE}

In the absence of a prospective study, it is possible only to make an educated guess at the incidence of VTE in association with travel. There are two possible approaches:

(1) Combine the data for the incidence of VTE in the general population (between 1.6 and 1.8 per 1000 per annum ${ }^{56}$ ) with the frequency of traveller's thrombosis amongst acute VTE cases extracted from the series quoted above (ranging from 3.2\% ${ }^{17}$ to $17.3 \%^{2}$ ). Possible explanations for the discrepancy in these numbers are the differing travelling habits of the populations studied and the different types of institutions in which the diagnosis was made - for instance, a district hospital as opposed to a military hospital or major trauma unit. It is accepted that there are grave dangers in making this kind of calculation, mixing the results from two studies and making assumptions from widely differing populations. Nevertheless, the very rough estimate obtained is $0.5-3$ per 10000 general population per annum.

(2) A rather more scientifically robust method undertaken by Dimberg et al was to examine the health records of a large, but relatively static, population of frequent travellers and to link these data with actual travel records. Of the staff at the World Bank, the possible travel associated incidence of DVT was between 0 and 4 per 10000 travellers. Interestingly, in this group the risk of DVT amongst travellers appeared to be about equal to that of non-travellers when adjusted for age and sex (L Dimberg et al, personal communication, 2000)

Although these two estimates are similar, it should be noted that the former refers to all VTE in the general population whilst the latter to DVT in a travelling population. Over a 12 month period every case of VTE treated in five hospitals serving a relatively fixed population of 650000 in the north of England was asked about travel in the four weeks prior to diagnosis. Twenty six cases were identified out of a total of 634 cases of VTE $(4.1 \%)$, giving an incidence of 0.4 per 10000 per annum in a population in north-east England. ${ }^{18}$

The above data refer, by definition, to patients who were both symptomatic and had presented to a medical institution. It is possible, perhaps likely, that there exists a further group, which may be significantly larger than the population studied, consisting of those who are either symptomatic and do not present to hospital or those who have an asymptomatic VTE. There is some evidence for the existence of both. Landgraf reported 


\begin{tabular}{|c|c|c|c|c|c|c|c|}
\hline & $\begin{array}{l}\text { Mercer }^{1} \\
(n=33)\end{array}$ & $\begin{array}{l}\text { Ferrari } i^{3} \\
(n=39)\end{array}$ & $\begin{array}{l}\operatorname{Rege}^{4} \\
(n=20)\end{array}$ & $\begin{array}{l}\text { Kesteven } \\
(n=26)\end{array}$ & $\begin{array}{l}\text { Milne }^{16} \\
(n=25)\end{array}$ & $\begin{array}{l}\text { Eklof }{ }^{2} \\
(n=44)\end{array}$ & $\begin{array}{l}\text { Eklof }^{2} \\
(n=36)\end{array}$ \\
\hline $\begin{array}{l}\text { Mean age } \\
\text { Median age } \\
\text { Age range } \\
\text { M:F } \\
\text { Total with at least one risk factor } \\
\text { Previous VTE } \\
\text { Malignancy } \\
\text { Recent surgery } \\
\text { Hormone treatment } \\
\text { Family history } \\
\text { Thrombophilia }\end{array}$ & $\begin{array}{l}48 \\
19-80 \\
27: 5 \\
74 \% \\
18 \% \\
18 \% \\
3 \% \\
3 \%\end{array}$ & 65.3 & $\begin{array}{l}40 \\
22-66 \\
5: 15 \\
75 \%\end{array}$ & $\begin{array}{l}61 \\
42-84 \\
12: 14 \\
87.5 \% \\
20 \% \\
5 \% \\
35 \% \\
30 \%\end{array}$ & $\begin{array}{l}51 \\
19-84 \\
\\
33 \% \\
4 \% \\
4 \% \\
12.5 \% \\
21 \%\end{array}$ & $\begin{array}{l}63 \\
32-86 \\
24: 20 \\
84 \%\end{array}$ & $\begin{array}{l}50 \\
23-83 \\
\\
34 \% \\
14 \% \\
9 \% \\
16 \%\end{array}$ \\
\hline
\end{tabular}

that all subjects in a simulated 12 hour flight developed swollen legs due to the retention of (on average) $1150 \mathrm{ml}$ fluid. ${ }^{19}$ In all cases the swelling had subsided within 24 hours. Also, as discussed below, there is some evidence to suggest that a recent flight may act as an additional risk for VTE. If this is so, the swollen legs after a long trip may be indicative of more than just accumulated fluid and be symptomatic of a more sinister thrombotic process.

Bergvist concluded from post mortem studies that up to $50 \%$ of cases of DVT and pulmonary embolism were asymptomatic. ${ }^{20}$ Thus, it is possible that some passengers do develop small venous thrombi during prolonged sitting which are "walked off" in the hours or days after travel. Although identification of this group is likely to be of benefit when assessing preventative measures, the discussions below are restricted to objectively diagnosed symptomatic cases.

\section{Who gets traveller's thrombosis?}

Pooling of the demographic data from the published series of case histories is not possible because of the different methods of case selection and of data presentation (table 2). Comparisons between the series, however, produce some interesting findings. In all series ages ranged from early adult to elderly with medians (where given) in the forties and means in the early sixties. Most studies have shown a youthful bias with a relative excess (compared with other forms of VTE) of cases aged $20-40$ years. The sex ratios in these series varied widely from $75 \%$ males $^{2}$ to $75 \%$ females, ${ }^{4}$ presumably reflecting the populations studied. The mean duration of travel, where stated, was of the order of six hours but with very large ranges. It should be noted that most series (with the exception of those from Honolulu) included trips as short as 1-2 hours. ${ }^{416}$

Risk factors for VTE were looked for in nearly all of these studies and at least one was found to be present in $75-80 \%$ of cases. The most common was previous VTE, followed by malignancy, hormone treatment, recent surgery, and family history of VTE. In only one study was a thrombophilia screen included and this showed $30 \%$ of cases with an abnormality, most commonly the factor $\mathrm{V}^{\text {Leiden }}$ mutation.

In our survey of traveller's thrombosis we observed that $66 \%$ of VTE cases were precipitated by the homeward leg of a round trip and all but two of the remainder had broken the outward journey. ${ }^{18}$ These cases were selected from anticoagulant clinics so the place of diagnosis was thought to be immaterial. If this finding is confirmed, it suggests that a recent flight may also be a risk factor for VTE.
The time elapsing between the start of the trip and developing symptoms also varied widely, although most studies included a group whose symptoms started during the journey. In all series the majority had developed symptoms within 96 hours, but occasional cases presented up to five weeks later.

\section{Does traveller's thrombosis behave in a similar} fashion to other forms of VTE?

None of the authors of these series noted any clinical differences between traveller's thrombosis and other cases of VTE. However, detailed examination of all these cases does suggest three (perhaps subtle) distinctions.

As mentioned above, there appears to be a relatively young group in each of these series, despite the age ranges being similar to those found in any series of VTE cases.

The frequency of symptomatic pulmonary embolism (as a proportion of all VTE) may be higher than expected ( $51 \%$ in one study). ${ }^{1}$ In a series of 3556 venographically diagnosed DVTs Schmitt et al found that 54 (1.5\%) were isolated to the popliteal vein, of which the great majority were thought to be due to traveller's thrombosis. $^{21}$ Of these, $44 \%$ had embolised. The authors subsequently showed in necroscopic studies that, when in the seated position, the popliteal vein develops transverse rippling. They concluded that this may be sufficiently damaging to the endothelium or cause sufficient alteration to flow to cause the initial thrombus formation.

Finally, the proportion of cases with pre-existing risk factors is higher than reported in series of VTE, although this may be for methodological reasons.

\section{Is flying more dangerous than other forms of travel, with respect to VTE? If so, what could be the causes?}

All the cases of traveller's thrombosis reported in the Honolulu studies occurred after a commercial flight. However, it should be noted that it is difficult to travel to Hawaii other than by air or by the patently nonthrombogenic sea cruise. On the other hand, in a study from Nantes, a provincial French capital, only nine of the 39 cases were associated with flying while the remainder had travelled by car or train. In our own study in Newcastle, also at some distance from the main airports, the proportions were 16 of 26 precipitated by flying whilst the remainder were related to car or coach travel.

Over the last two decades many theories have been proposed as to possible additional causes of VTE after 


\begin{tabular}{|c|c|c|}
\hline Risk categories & & Prophylaxis \\
\hline Low risk & $\begin{array}{l}\text { Age over } 40 \text {; obesity; active inflammation; polycythaemia; } \\
\text { recent minor surgery (last three days) }\end{array}$ & $\begin{array}{l}\text { Advice about mobilisation and hydration } \pm \text { support } \\
\text { tights/non-elasticated long socks }\end{array}$ \\
\hline Moderate risk & $\begin{array}{l}\text { Varicose veins, heart failure (uncontrolled); myocardial } \\
\text { infarction (recent); hormone therapy; pregnancy/postnatal; } \\
\text { lower limb paralysis; recent lower limb trauma (six weeks) }\end{array}$ & As above + aspirin \pm graduated compression stockings \\
\hline High risk & $\begin{array}{l}\text { Previous VTE; known thrombophilia; recent major surgery } \\
\text { (six weeks); previous CVA; malignancy; family history of VTE }\end{array}$ & $\begin{array}{l}\text { As above, but low weight molecular heparin instead } \\
\text { of aspirin }\end{array}$ \\
\hline
\end{tabular}

flying, including dehydration, excessive alcohol, poor air quality, time zone changes, seasonal shifts, and hypoxia. ${ }^{13202223}$ However, it is difficult to find firm experimental evidence in support of these theories, with two exceptions.

In 1976 Carruthers et al subjected the 13 crew members on a 20 hour flight from Buenos Aires to London (and the chief medical officer of the airline and his wife who were passengers) to four hourly urine and blood tests. ${ }^{22}$ The main purpose of this study was to examine stress levels, but significantly reduced urine output volumes and raised urinary osmolality compared with nonflying controls were demonstrated. Although no tests were performed to detect clinical dehydration, there can be little doubt that these subjects were dry.

Bendz et al recruited 12 healthy men to live in a hypobaric chamber built as an apartment for the purposes of training competitive skiers for a week. ${ }^{24}$ Blood samples were collected at intervals and the pressure altered to simulate first $2000 \mathrm{~m}$ (typical of long distance flights) and subsequently to $4500 \mathrm{~m}$ representing extreme mountain climbing. The first change, from sea level to $2000 \mathrm{~m}$, was made over 5-10 minutes and was associated with subtle but statistically significant activation of the tissue factor pathway. These activation markers returned to normal whilst $2000 \mathrm{~m}$ pressure was maintained and did not reappear in the climb to $4500 \mathrm{~m}$. Unfortunately, this study did not include a control group, so it is difficult to know if the changes were due to the pressure or hypoxic change, as concluded by the authors, or to being placed in a hypobaric chamber for a week.

It seems unlikely that either reduced oxygen tension or reduced atmospheric pressure are themselves aetiological factors for VTE, as we would otherwise expect reports of an increased incidence of VTE in the many people living at these altitudes or in patients with hypoxic lung disease. This last issue has been specifically examined by Schonhofer et al who found an increased incidence of DVT in patients suffering an acute exacerbation of chronic obstructive pulmonary disease, but attributed this to immobility as blood gas tensions were no different from those of controls. ${ }^{25}$

There appears to be a consensus view that seated immobility is a risk factor for VTE and that being cramped is likely to aggravate this immobility. For many of us, air travel is the most likely reason for such prolonged seated immobility. Rapid changes in pressure or oxygen tension and mild degrees of dehydration may be aggravating factors in flight. However, other forms of transport have been suspected to precipitate thrombosis.

What can be recommended?

The little evidence available suggests that sitting acts as only one of several risk factors. This fits the "multiple hit" model proposed by Rosendaal. ${ }^{8}$ There are two corollaries which follow if this model is accepted: (1) those with normal venous and haemostatic systems will probably not experience VTE, even on long journeys; and (2) multiple trips will be slightly more dangerous than single trips, as other risk factors accumulate. Unfortunately, it seems unlikely that we will ever be in a position to know all the risk factors involved and therefore that an individual's haemostatic system is, in fact, normal. Nevertheless, and in line with other forms of VTE, in those cases in which known risk factors are present prophylaxis should be offered. The level of prophylaxis will depend on the perceived level of risk (table 3).

To those with no obvious risk factors the general advice of frequent and regular stretching exercises, changes in position, and walking around the cabin seems sensible, within the constraints of air safety.

With this in mind, the airlines should be encouraged to minimise enforced immobility and to allow more leg movement. This may include redesign of seating arrangements and strict rules on hand luggage placement. However, until controlled prospective studies are published there will be no firm foundation for any such advice.

\section{LEARNING POINTS}

* Current evidence suggests a strong link between travel and venous thrombosis but no prospective clinical study has yet been published

* The annual incidence of this complication may be estimated (roughly) at 0.5-3 per 10000 general population

* The majority of patients with traveller's thrombosis appear to have other risk factors for venous thrombosis prior to their journey

* These results are consistent with Rosendaal's "multiple hit" theory of the aetiology of venous thrombosis 


\section{Conclusions}

There is a very wide spectrum of opinions on the subject of traveller's thrombosis ranging from a disinclination to accept the entity at all, awaiting firmer evidence, to the view that the majority of passengers on long haul flights carry small venous thrombi off the plane.

Much of the above is supposition, based on existing literature but lacking solid experimental data. Many of these questions will be answered by properly conducted prospective clinical study, examining prothrombotic markers before and after travel.

1 Mercer A, Brown JD. Venous thromboembolism associated with air travel: a report of 33 patients. Aviation, Space Environ Med 1998;69: $154-7$.

2 Eklof B, Kistner RL, Masuda EM, et al. Venous thromboembolism in association with prolonged air travel. Dermatol Surg 1996;22:637-41.

Ferrari E, Chevallier T, Chapelier A, et al. Travel as a risk factor fo thromboembolic disease. A case control study. Chest 1999;115:440-4

4 Rege KP, Bevan DH, Chitolie AC, et al. Risk factors and thrombosis after airline flight. Thromb Haemostas 1999;81:995-6.

5 Nordstrom M, Lindblad B, Bergqvist $\mathrm{D}$, et al. A prospective study of the incidence of deep-vein thrombosis within a defined urban population. F Intern Med 1992;232:155-60.

6 Hansson PO, Werlin L, Tibblin G, et al. Deep vein thrombosis and pulmonary embolism in the general population. Arch Intern Med 1997 157:1665-70.

7 Carter CJ. The natural history and epidemiology of venous thrombosis. Prog Cardiovasc Dis 1994;36:423-38.

8 Rosendaal FR. Venous thrombosis: a multicausal disease. Lancet 1999; 353:1167-73.
9 Virchow R. Gessamelte Abhanlungen zur Wissenschaftlischen Medicine. Frankfurt: Meidinger, 1856

10 Simpson K. Shelter deaths from pulmonary embolism. Lancet 1940;ii: 744 .

11 Homans J. Thrombosis of the deep leg veins due to prolonged sitting. N Engl f Med 1954;250:148-9.

12 Eschwege V, Robert A. Strikes in French public transport and resistence o activated protein C. Lancet 1996;347:206

13 Beighton PH, Richards PR. Cardiovascular disease in air travellers. British Heart $\mathcal{F}$ 1968;30:367-71.

14 Sarvesvaran R. Sudden natural deaths associated with commercial air travel. Med SciLaw 1986;1:35-8.

15 Cruickshank JM, Gorlin R. Air travel and thrombotic episodes: the economy class syndrome. Lancet 1988;ii:497-8.

16 Milne R. Venous thromboembolism and travel: is there an association? $7 R$ Coll Phys London 1992;26:47-9.

17 O'Donnell D. Thromboembolism and air travel. Lancet 1988;ii:797.

18 Kesteven P, Robinson B. Venous thrombosis and air travel. Aviation Space Environ Med 2000 (in press).

19 Landgraf H, Vanselow A, Schulte-Huermann D, et al. Economy class syndrome: rheology, fluid balance and lower leg edema during a simulated 12-hour long distance flight. Aviation Space Environ Med 1994;65:930-5.

20 Bergqvist D. Thrombosis: clinical practice and perspectives. Oxford: Oxford Clinical Communications, 1990.

21 Schmitt HE, Mihatsch MJ. Thrombosis of the popliteal vein. Cardiovasc Intervent Radiol 1992;15:234-9.

22 Carruthers M, Arguelles A, Mosovich A. Man in transit: biochemical and physiological changes during intercontinental flight. Lancet 1976; i: $977-80$.

23 Forbes CD, Johnston RV. Venous and arterial thrombosis in airline passengers. $7 R$ Soc Med 1998;91:565-6.

24 Bendz B, Rostrup M, Sevre K, et al. Effect of hypobaric hypoxia on tissue factor induced coagulation. Thrombosis and Haemostasis ISTH Congress, Washington, 1999

25 Schonhofer B, Kohler D. Relevance of deep venous thrombosis of the leg in patients with acute exacerbated COPD. Pneumologie 1999;53: $10-14$ 